\title{
WIND DATA ANALYSIS AND WIND FLOW SIMULATION OVER LARGE AREAS
}

\author{
ANGEL TERZIEV- Lecturer, Assoc. Prof., PhD, Technical University of Sofia, Faculty of Power Engineering and \\ power Machines, Bulgaria, e-mail: aterziev@tu-sofia. \\ IVAN ANTONOV - Prof., D. Sc., Technical University of Sofia, Faculty of Power Engineering and power \\ Machines, Bulgaria, e-mail: antonov94116@yahoo.com \\ ROSITSA VELICHKOVA - Assist. Prof., Technical University of Sofia, Faculty of Power Engineering and power \\ Machines, Bulgaria, -mail: rositsavelichkova@abv.bg
}

\begin{abstract}
Increasing the share of renewable energy sources is one of the core policies of the European Union. This is because of the fact that this energy is essential in reducing the greenhouse gas emissions and securing energy supplies. Currently, the share of wind energy from all renewable energy sources is relatively low. The choice of location for a certain wind farm installation strongly depends on the wind potential. Therefore the accurate assessment of wind potential is extremely important. In the present paper an analysis is made on the impact of significant possible parameters on the determination of wind energy potential for relatively large areas. In the analysis the type of measurements (short- and long-term on-site measurements), the type of instrumentation and the terrain roughness factor are considered. The study on the impact of turbulence on the wind flow distribution over complex terrain is presented, and it is based on the real on-site data collected by the meteorological tall towers installed in the northern part of Bulgaria. By means of CFD based software a wind map is developed for relatively large areas. Different turbulent models in numerical calculations were tested and recommendations for the usage of the specific models in flows modeling over complex terrains are presented. The role of each parameter in wind map development is made. Different approaches for determination of wind energy potential based on the preliminary developed wind map are presented.
\end{abstract}

Keywords: turbulence modeling, wind map, CFD modeling, wind data processing

\section{Introduction}

The precise determination of wind potential over certain site depends on many parameters. In energy yield estimation, when available, the following should be considered: long term wind data collected by the measuring equipment of the meteorological institute, aerial and naval aviation. Most of the above mentioned equipment is old and not very accurate but gives general information about wind potential. As soon as the site has been selected a precise long term (with meteorological mast) measurements should be performed. At least two years on the specific site measurements are needed in order to achieve accurate data analysis. The measuring set masts include wind speed sensors (anemometers), wind direction sensors (wind vane), barometric sensors, temperature sensors, and humidity sensors. At least hourly measurements are required. Processed long term on-site data are used for determination of wind shear, wind rose, relief roughness, turbulence, etc. For small and complex areas different approaches for wind simulations should be applied [1] [2] [3] [4]. For relatively large flat areas, however with the appropriate approximation technique, the data can be distributed away with reasonable certainty. For more complex sites a similar approach cannot be applied. In order to predict the flow distribution, a specific turbulent model concerning the terrain orography should be applied in the CFD specialized software. Current work shows possibilities of using the different CFD based software and turbulent models to predict the wind flow distribution over complex terrains and further analysis for covering larger areas. 


\section{Long term wind data and wind measurement techniques}

Here are briefly described the types of sources of long term wind data, on-site meteorological tall towers and specific measurement equipment for collection of wind data. Some techniques for the analysis of wind data are presented. Special attention is paid to the important wind parameters affecting the wind flow distribution over the terrain.

\subsection{Long term wind data}

The wind data that have been collected for a long period of time (at least 3 years) for a specific location are called long term. Most of the long term data are hourly. Some of the results are summarized (average wind speed and wind rose). Below are presented the different types of long term data sources.

\subsubsection{Bulgarian Academy Science (BAS) long term database [5]}

The wind data accessible through the BAS database are from 119 meteorological tall towers located on the territory of Bulgaria. The meteostations collect data for the wind speed and direction at $10 \mathrm{~m}$ above the Earth surface. The data are available for a long period of time - more than 30 years. The data are summarized (averaged within 7, 14 and 21 hours). The wind velocity is a parameter that could vary rapidly for a short period of time. This is the reason the abovementioned summarized data to be accepted as reliable. On the other hand the wind direction parameter changes less (in most of the cases seasonally). Therefore those data can be accepted as referent for on-site data. Unclear! If data analysis shows a high level of correlation, then the results can be assumed as representative and with a greater degree of reliability and may be used in determination of probable energy production.

\subsubsection{Meteorological tall towers with on-site application}

When certain site is selected on-site measurements are needed. There are generally two types of commercial tall towers used for the collection of wind data: tubular and lattice wind masts. The constructions are presented in Figure 1a and $b$.

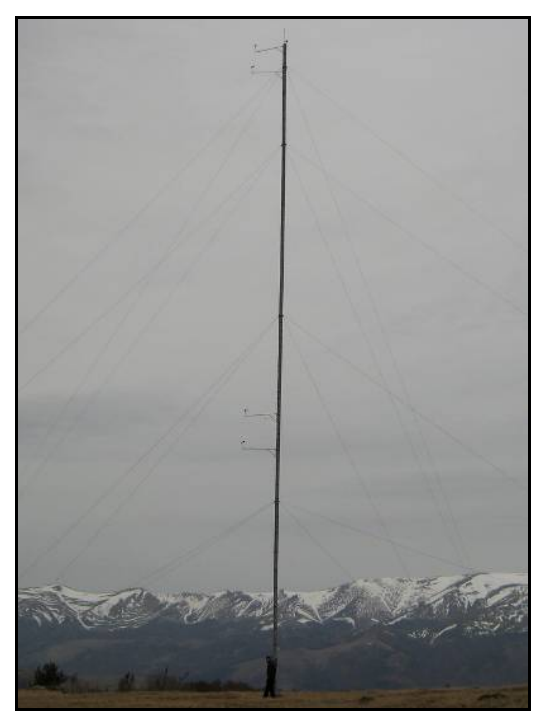

a)

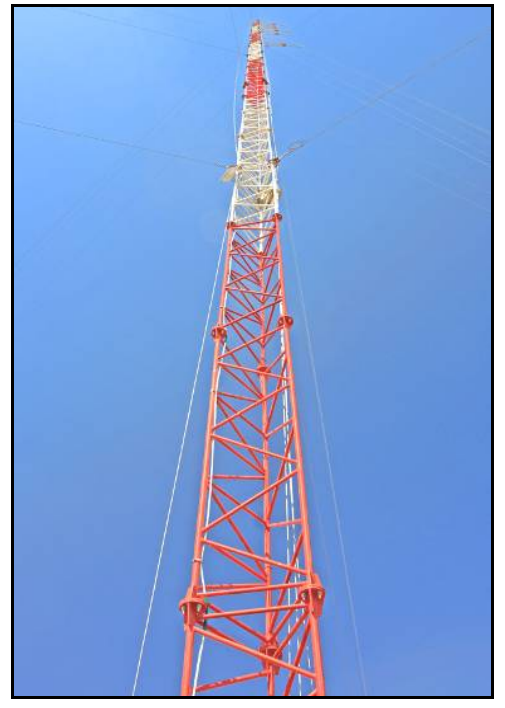

b)

Fig. 1- a) tubular mast, b) lattice mast

The tubular masts generally consist of steel tubes attached to each other reaching $80 \mathrm{~m}$ in height. The construction and mechanism of erection allow the masts to be easily installed on complex terrains. The tube shape has a minor influence on the measuring equipment. The lattice tall tower consists of many sections. This type of construction allows heights up to $120 \mathrm{~m}$. It is much more reliable than the steel tube tower because of its higher stability. The installation of such equipment however is accomplished by means of heavy equipment which is not always able to reach the site by itself. 
The direction and the distance of installation of some measuring equipment on the mast are very important. The study in the field shows that when a tube is passed by the wind flow, eddies are destroyed on a distance of 7 to 10 times the diameter of the steel tube. This is the reason why the equipment should be mounted after the disturbed wind flow region. During the process of the installation of the measuring equipment the respective standards should be considered [6].

Below are presented the most commonly used devices for measuring the wind speed (Fig. 2a, $b$ and c), the wind direction (Fig. 2d), temperature (Fig 2e), and the atmospheric pressure (Fig. 2f) [13]. Additional information about the measuring equipment is presented in [7].

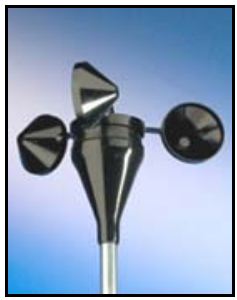

a)

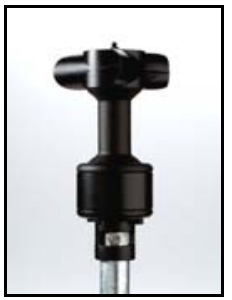

b)

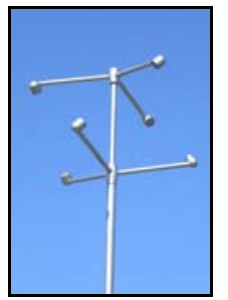

c)

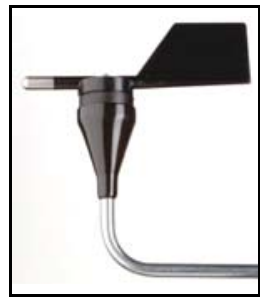

d)

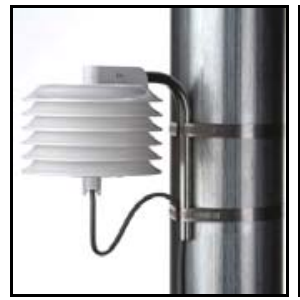

e)

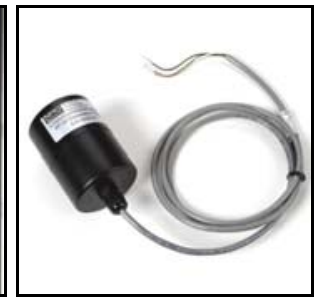

f)

Fig. 2 - a) cup anemometer, b) heated anemometers, c) ultrasound anemometers, d) wind vane, e) temperature sensor, f) barometric sensor [13]

\subsubsection{Wind data interpretation}

In order to evaluate the accuracy and reliability of the on-site data a correlation with the long term data is needed. As it was discussed above the correlation should be considered only with the respect of wind direction. In figure $3 \mathrm{a}$ the wind rose generated by the data collected with the meteorological tall tower is presented, and in Fig. $3 \mathrm{~b}$ the wind rose based on the 30years period data is represented.

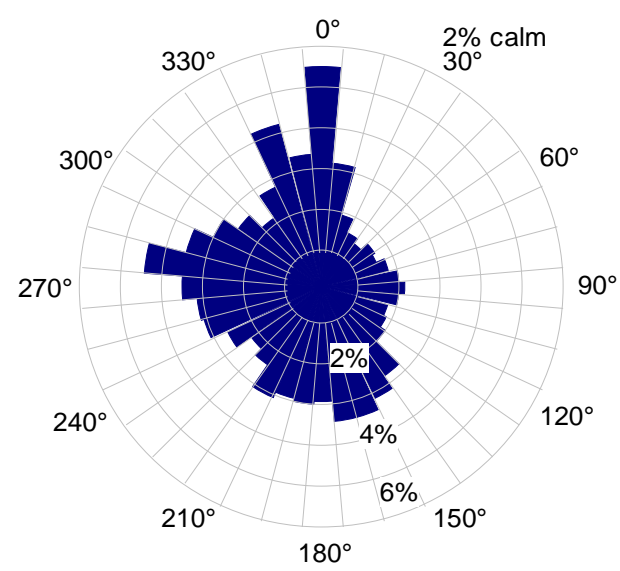

a)

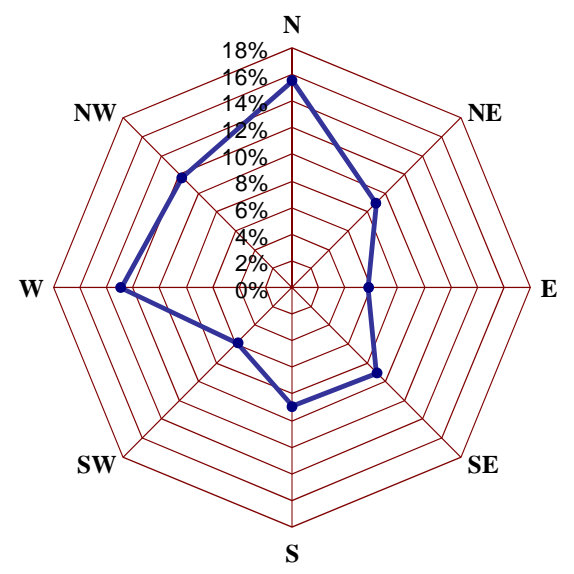

b)

Fig. 3 - a) wind rose based on the hourly on-site data collected with meteorological $60 \mathrm{~m}$ tall tower, b) 30 years long term data

Those two types of data were collected at a distance $30 \mathrm{~km}$ apart. The $60 \mathrm{~m}$ mast was installed in Northwestern part of Bulgaria in the vicinity of village Brest. The data were collected for at least one year period. Because of the flatness of the terrain a good correlation between on-site and long term data occurred (Fig. 3). The compared data are presented in Table 1. The prevailing wind directions were North, West and South-West. The correlation factor between those two sets of data is above $70 \%$. The general conclusion that can be made is the data collected with the $60 \mathrm{~m}$ mast are not exceptional and they are representative for the specific location. Hence further analysis about energy yield estimation based on the on-site collected data will be reliable. 
Directional frequency distribution. The on-site data are collected in the vicinity of Brest village

\begin{tabular}{|c|c|c|}
\hline & \multicolumn{2}{|c|}{ Directional frequency distribution, \% } \\
\hline & $60 \mathrm{~m}$ mast & BAS long term data \\
\hline $\mathbf{N}$ & 17.29 & 15.58 \\
\hline NE & 7.10 & 8.97 \\
\hline $\mathbf{E}$ & 8.85 & 5.75 \\
\hline SE & 11.15 & 9.05 \\
\hline S & 14.53 & 8.89 \\
\hline SW & 11.94 & 5.82 \\
\hline $\mathbf{W}$ & 16.89 & 12.91 \\
\hline NW & 12.24 & 11.73 \\
\hline
\end{tabular}

The layout (micro-sitting) of the wind turbines in the wind farm is generally based on the prevailing wind direction. Due to the directional statistic and the correlation factor, is possible to be properly organized the wind turbines on the site. The precise micro-sitting of the wind turbines will decrease losses because of the mutual influence and will increase the energy utilization from the wind on the site.

\section{Site specifics. Relief modeling. Roughness factordetermination.}

The precise and reliable on-site data collected by the meteorological mast is the first step in modeling of the fluid flow over the terrain. The complexity of the relief around the measurement point defines the wind flow distribution above the surface. In order to get accurate wind shear, on-site measurement of at least three different heights is needed. The flow distribution over the terrain depends on the relief complexity. In case of flat terrain by using the simple mathematical methodology the data can be distributed around the measuring point fairly accurately. When the terrain is complex such approach cannot be applied.

There are many software products available on the market that can be used for wind flow modeling. Most of them, however, because of the simplified mathematical models used in calculations, cannot be considered reliable.

An approach about the site geometry modeling and wind flow simulation is presented below. The 3D model of the site can to be constructed on the basis of the topographic map of the site. Depending on the size of the spot different scale topographic maps should be considered. The wind flow distribution above the ground strongly depends on the surrounding orography. The study shows that at least $15 \mathrm{~km}$ beyond the site are needed for the correct data (Figure 4a). The digitized topographic map of a specific site generated with specialized software [8] is presented in Figure 4b.

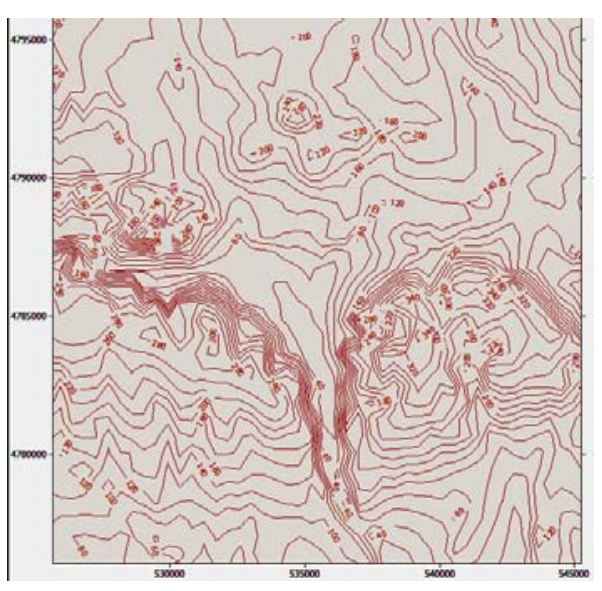

a)

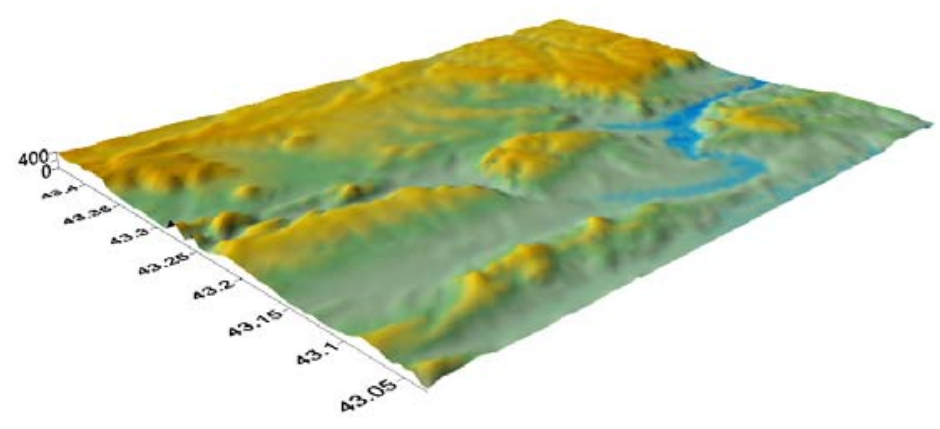

b)

Fig. 4 - a) topographic map, b) 3D view of the site

Another method for the construction of the 3D map of the site is by using the Geographic Orographic info database [9]. One of the possible options is the data for the site orography to be 
extracted in ASCII XYZ format. There are different approaches of connecting the set of points into surface. For complex terrains a Kriging method [10] is recommended.

When the $3 \mathrm{D}$ model of the site is generated a roughness factor should be determined. The roughness class is a dimensionless number based on the value of the surface roughness. With the following equation the roughness class RC could be defined [11]:

$$
C= \begin{cases}3.91248+\ln z_{0} / \ln 3.33333 & \text { if } z_{0}>0.03 m \\ 1.69982+\ln z_{0} / \ln 150 & \text { if } z_{0} \leq 0.03 m\end{cases}
$$

where $\mathrm{z} 0$ is the surface roughness in $\mathrm{m}$.

The following Table 2 [14] lists the terrain types, characteristic of various values of roughness class.

Table 2

Terrain types characteristic of various values of roughness class [14]

\begin{tabular}{|c|c|l|}
\hline Roughness Class & Surface Roughness (m) & \multicolumn{1}{c|}{ Landscape Type } \\
\hline 0 & 0.0002 & Water surface \\
\hline 0.5 & 0.0024 & $\begin{array}{l}\text { Completely open terrain with a smooth surface, e.g. concrete } \\
\text { runways in airports, mowed grass, etc. }\end{array}$ \\
\hline 1 & 0.03 & $\begin{array}{l}\text { Open agricultural area without fences and hedgerows and } \\
\text { very scattered buildings. Only softly rounded hills. }\end{array}$ \\
\hline 1.5 & 0.055 & $\begin{array}{l}\text { Agricultural land with some houses and 8m tall sheltering } \\
\text { hedgerows with a distance of approx. 1250m. }\end{array}$ \\
\hline 2 & 0.1 & $\begin{array}{l}\text { Agricultural land with some houses and 8m tall sheltering } \\
\text { hedgerows with a distance of approx. 500m. }\end{array}$ \\
\hline 2.5 & 0.2 & $\begin{array}{l}\text { Agricultural land with many houses, shrubs and plants, or } \\
\text { 8m tall sheltering hedgerows with a distance of approx. } \\
\text { 250m. }\end{array}$ \\
\hline 3 & 0.4 & $\begin{array}{l}\text { Villages, small towns, agricultural land with many or tall } \\
\text { sheltering hedgerows, forests and very rough and uneven } \\
\text { terrain. }\end{array}$ \\
\hline 3.5 & 0.8 & Larger cities with tall buildings. \\
\hline 4 & 1.6 & Very large cities with tall buildings and skycrapers. \\
\hline
\end{tabular}

\section{Wind flow modeling over the terrain}

When it comes to modeling of the fluid flow over a not very large area for the analysis of the energy potential, especially concerning the complex terrains, numerical simulations are always good to be performed with the appropriate software. From the variety of the software available on the market the data generated by the Ansys (Fluent package) [15] show good correlation with the experimental ones.

An example of a wind flow simulation over complex terrain by the means of Fluent software is presented below. The calculations started with the construction of the geometric model as it was described in section 3 of the present paper. The second step is the assignment of the boundary conditions (Fig. 5).

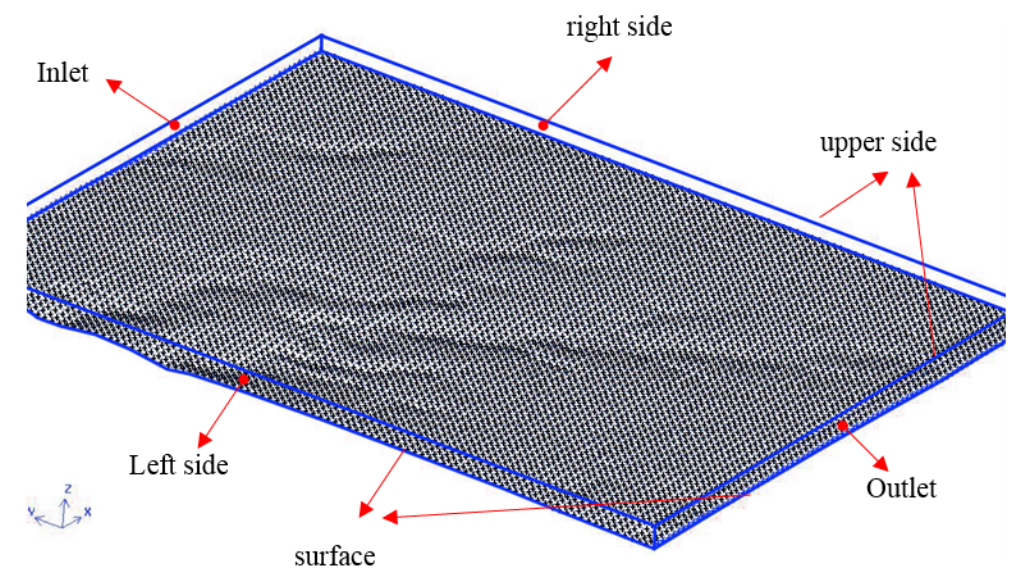

Fig. 5 - Elements and specifics of the model 
The accepted boundary conditions are presented in Table 3

Table 3

Types of elements and the respective boundary conditions

\begin{tabular}{|c|c|}
\hline Element & Boundary condition type \\
\hline Inlet & Velocity inlet \\
\hline Left side & Symmetry boundary condition \\
\hline Right side & Symmetry boundary condition \\
\hline Outlet & Outflow \\
\hline Surface & Wall with respective functions \\
\hline Upper side & Symmetry boundary condition \\
\hline
\end{tabular}

The performed numerous numerical simulations show that the turbulent model that best describes such types of flows is $k-\varepsilon$. Here the turbulent kinetic energy is noted with $k$, and $\varepsilon$ is the dissipation rate. Setting up the initial velocity is according to the data obtained by the field measurements. For initial turbulent kinetic energy $k=0,9 \mathrm{~m}^{2} / \mathrm{s}^{2}$ is accepted. In Figure 6 the wind distribution over complex terrain (at $110 \mathrm{~m}$ height) is presented as a result of accomplished numerical simulations.

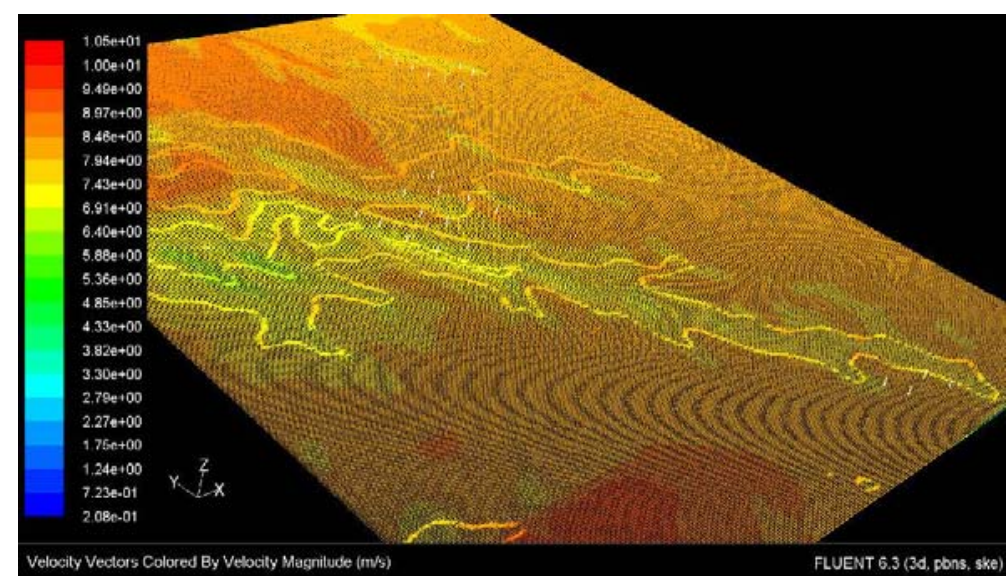

Fig. 6 - Wind distribution over the terrain (numerical calculations)

\section{Wind map development for large areas}

In order to be created a wind atlas (map) for a large area, extensive wind data for many points are needed. Under the Project [12] 15 tall towers $(60 \mathrm{~m})$ were installed in different points in Northern part of Bulgaria (Fig. 7). The data obtained by the wind towers are for a period greater than one year.

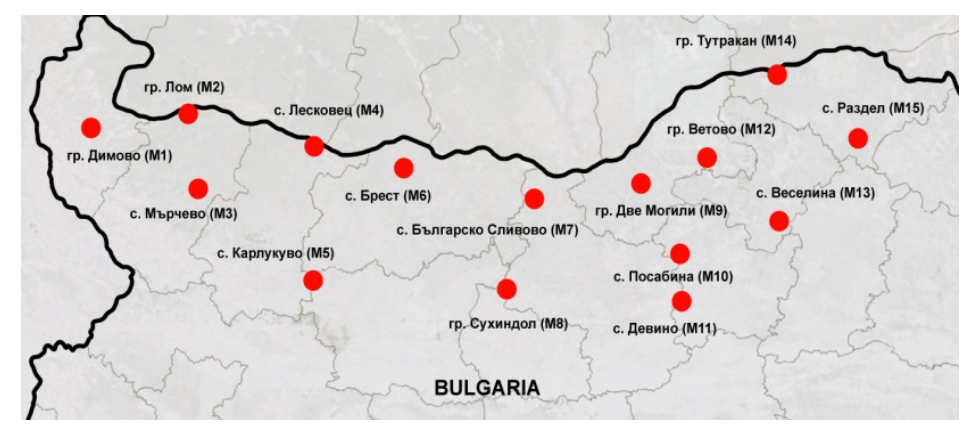

Fig. 7 - Location of the meteorological tall tower [17]

The correlation factors based on the data obtained by the masts for each two points show the following: Correlation coefficient between mast M1, M2, M4 and M6 is above $88 \%$. This will allow to be created the reliable velocity field between the separate points. The same analysis can be made for points „M1, M3, M5, M8”, „M7, M9, M12 and M14”, as well as „M10, M11” and „M13, M15”. Lower correlation coefficients occur for the masts located close to the Danube 
river coast and near the countryside where the relief is very complex. The simplified atlas of the region for the velocity field (Fig. 8) is created on the basis of the on-site data and the mathematical approach of triangulation with linear interpolation. Figure 9 presents the wind distribution for smaller area obtained by using the numerical solution approach.

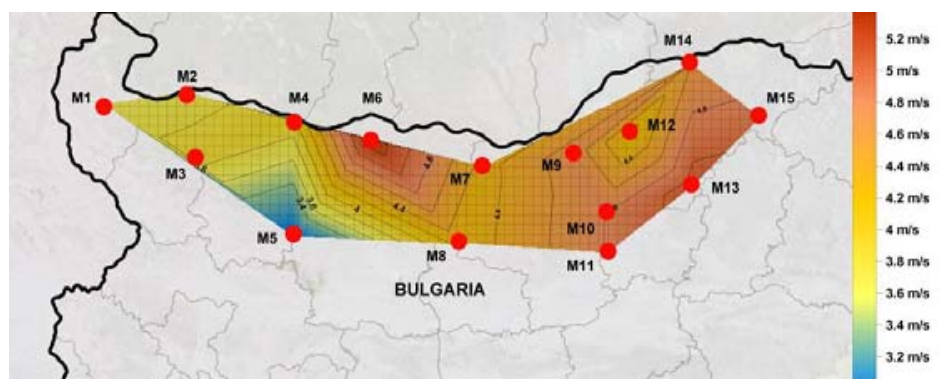

Fig. 8 - Wind flow distribution based on the triangulation with linear interpolation methodology

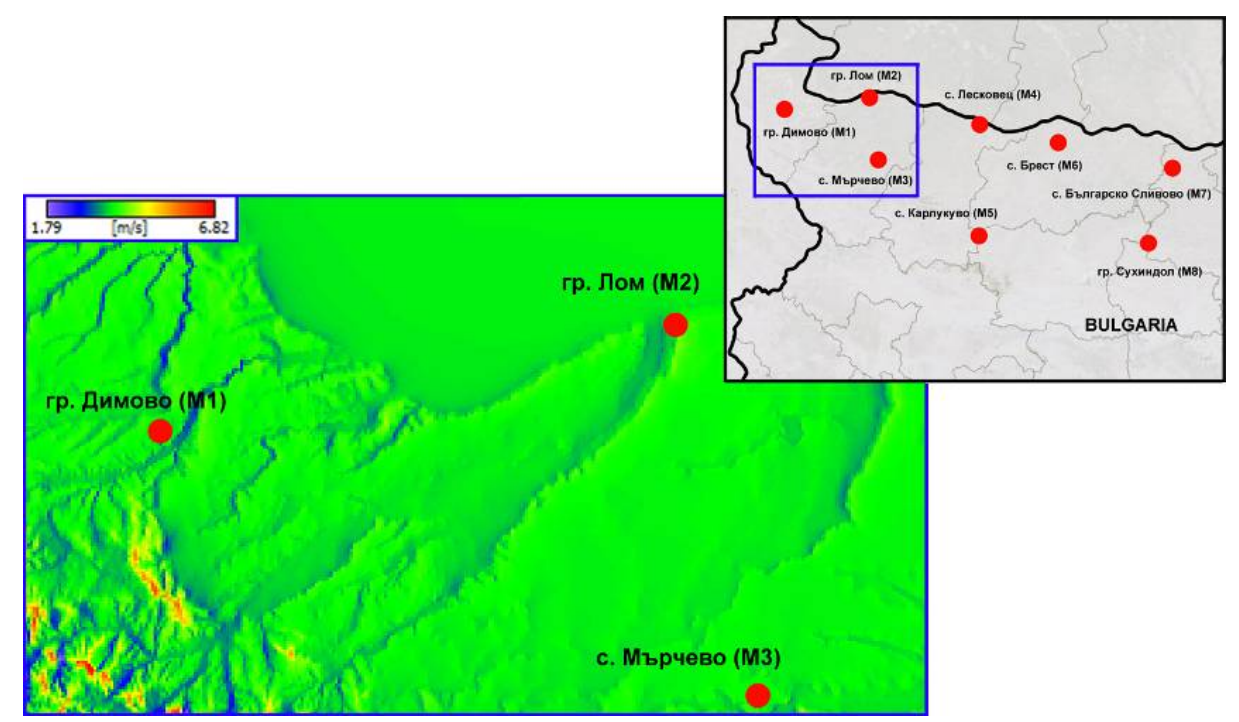

Fig. 9 - Numerical results of wind distribution over the complex terrain

\section{Conclusions}

This paper presents an analysis of the types of data and measurements for the analysis of wind potential. The wind parameters that affect mostly the wind flow distribution are discussed. For this purpose the methods for digitizing the maps - construction of the 3D relief of the site with further numerical simulations are briefly described. Some guidelines about the usage of certain software products for modeling of the wind flow over small and large scale areas are presented. The appropriate turbulent models used in numerical simulations are identified.

\section{References}

[1] O'Sullivan, J. (2012). Modeling wind flow over complex terrain, Ph. D dissertation, University of Auckland,.

[2] O’Sullivan J., Pecnik R., Iaccarino G. (2010). Investigating turbulence in wind flow over complex terrain, Procceding of the summer programm, (pp. 129-)

[3] Eidsvik, K. J., (2005) A system for wind power estimation in mountainous terrain prediction of Askervein hill data. Wind Energy 8, (2), (pp. 237-249)

[4] Loureiro, J., Monteiro A., Pinho F., Silva Freire A. (2009). The effect of roughness on separating flow over two-dimensional hills. Experiments in Fluids 46 (4), (pp. 577-596.)

[5] Terziev A., Petrov P., Ivanov A. (2009). Study and analysis of the possibilities of using the referent wind measurement data in wind potential assessment, Proceeding of National Conference with International Participation, "Mechanisms, machine techniques, mechanical and energy technologies"., 26-28 June, Sliven 2009y., magazine "Mechanics of machines", (pp. 46-49), ISSN 0861-9727.

[6] Standard for the preparation of wind energy assessments. German wind energy association. Advisory board for wind resource. 2. (Edition 2005-02). 
[7] Petrov P., Terziev A., Ivanov A. (2009). Types of meteorological masts and measuring equipment applied in the study of wind potential Proceeding of National Conference with International Participation, "Mechanisms, machine techniques, mechanical and energy technologies"., 26-28 June, Sliven 2009., magazine "Mechanics of machines", (pp. 42-45), ISSN 0861-9727.

[8] http://www.goldensoftware.com/products/didger/uses.shtml

[9] http://dataforwind.com/extraction.php

[10] Oliver M. A., Webster R., (1990). Kriging: a method of interpolation for geographical information systems, International Journal of Geographical Information Systems, Volume 4, Issue 3, (pp. 312-332).

[11] www.windpower.org

[12] Scientific Project № ДО02-48/10.12.2008, Technical University of Varna, "Development of specilized scientific infrastructure of the study of the potential of solar and wind", Supported by the Bulgarian Ministry of Education.

[13] www.nrgsystems.com

[14] http://cr.middlebury.edu/es/wind group/terrain.htm

[15] www.ansys.com, The simulations are performed in the Rousse University „Angel Kantchev” scientific center. 